\title{
A LOUCURA, O DEMÔNIO E A MULHER: SOBRE A CONSTRUÇÃO DE DISCURSOS NO MUNDO MEDIEVAL
}

THE MADNESS, THE DEMON AND WOMEN: SPEECHES ON CONSTRUCTION IN MEDIEVAL WORLD

\author{
Jarbas Dametto* \\ jarbasdametto@gmail.com \\ Rosimar Serena Siqueira Esquinsani** \\ rosimaresquinsani@upf.br
}

RESUMO: A loucura recebeu olhares e tratamentos distintos nos diversos momentos históricos e contextos sociais. Partindo deste ponto, realizou-se uma pesquisa calcada no método analíticoreconstrutivo, tornada com efeito através de uma bibliográfica temática, objetivando apreender alguns dos sentidos e interpretações vinculadas a loucura na cultura ocidental, em especial no mundo medievo. Assim o texto aborda discursos que vinculam a loucura, a doutrina demonista e a mulher, apontando possíveis ligações entre as relações de gênero, a experiência feminina, os discursos pronunciados sobre a loucura e os modos como tais enunciados reforçavam as relações de poder e sujeição entre os sexos na Idade Média.

PALAVRAS-CHAVE: Loucura, Gênero, Idade Média.

ABSTRACT: Madness received different looks and treatments in different historical and social contexts moments. From this point, one grounded research was carried out in the analytical-reconstructive method, made indeed through a literature theme, aiming to learn some of the meanings and interpretations related of the madness in Western culture, especially in the medieval world. So the text addresses speeches linking madness, demoness doctrine and the woman, pointing possible links between gender relations, women's experience, the speeches about the madness and the ways such statements reinforced the relations of power and subjection between sexes in the Middle Ages.

KEY-WORDS: Madness, Gender, Middle Ages.

\section{Introdução}

O termo "loucura", nos dias atuais, pode remeter a denominação vulgar atribuída a condições ligadas à precariedade da saúde mental ou a situações de sofrimento psíquico, ou seja, a uma diversa gama de diagnósticos relacionados a áreas do saber médico ou psicológico. Do mesmo modo, esta condição é objeto do discurso jurídico, que a compreende como uma experiência ou um estado, no qual estatuto jurídico do sujeito é posto em questão, dado que se concebe a loucura como ausência de razão ou lucidez, ou seja, uma privação de qualquer possibilidade de livre-arbítrio ou de adequado discernimento acerca dos próprios atos.

Ambas as concepções, acima propostas resumidamente, vinculam a loucura a campos do saber institucionalizados, que, embora possuam raízes remotas, ganharam a forma e a pertinência social que conhecemos há poucos séculos, na Modernidade. Tais perspectivas, indubitavelmente, não podem servir de lente para a análise que se pretende aqui, cabendo

\footnotetext{
* Doutor em Educação, professor do Programa de pós-graduação em envelhecimento Humano-UPF.

** Doutora em Educação, professora do programa de pós-graduação em Educação - UPF
} 
recorrer a olhares distintos daqueles que classificaram o enlouquecimento como "doença". Logo, deve-se considerar que a loucura, enquanto experiência e não objeto do saber médico, jurídico ou psicológico, acompanha a humanidade desde os momentos mais remotos da civilização, e que em cada período histórico ela recebeu uma conotação específica vinculada às características culturais vigentes, gerando sobre o fenômeno distintas formas de classificação e tratamento. Sujeitos loucos, possuídos, pervertidos, insanos, alienados, dementes, excêntricos ou doentes, dentre outras denominações possíveis, foram submetidos a procedimentos que incluíam benzimentos, exorcismos, contenção e medicalização ou, e em casos mais extremos, a exclusão através do banimento ou execução pela fogueira.

O texto que aqui se apresenta, em termos gerais, empreende a retomada de alguns dos sentidos e interpretações acerca desta experiência subjetiva e social na cultura do ocidente ao longo da Idade Média, e em específico, pontua a relação entre a experiência da loucura e a condição feminina, presente em importantes escritos filosófico-religiosos. A retomada histórica da questão da loucura mostra-se conveniente frente à possibilidade de desnaturalizar o problema, expondo os vínculos existentes entre as suas diversas interpretações e os preceitos éticos e morais de cada época, assim como os posicionamentos sexistas em relação ao tema exposto, e os discursos e práticas daí resultantes.

Para tal retomada, o texto utiliza-se de alguns estudos sobre a loucura e suas vicissitudes ao longo da história, focalizando conceitos, ideias e procedimentos relativos a ela, além disso, lança-se mão de textos clássicos da referida época. Nesta revisão de literatura foram priorizadas algumas das obras que tratam da questão a partir das relações de gênero e/ou da história com foco no mundo medieval.

\section{O mundo medievo: a loucura, o demônio e a mulher}

Considerando que "anomalias físicas ou mentais, deformações congênitas, amputações traumáticas, doenças graves e de consequências incapacitantes, sejam elas de natureza transitória ou permanente, são tão antigas quanto a própria humanidade" (SILVA, 1987, p. 21), o resgate dos dispositivos político-discursivos construídos em torno da loucura na Idade Média resta por somar esforços e produzir interpretações acerca dos processos de subjetivação - e conceitualização - dos diferentes. No caso específico da Idade Média, tais processos remetem a uma característica peculiar: a vinculação explícita entre a loucura, o demônio e o gênero, como faces/interpretações de um suposto mesmo fenômeno. 
Isto porque a compreensão acerca da loucura na Idade Média pareceu sofrer um retorno ao misticismo, em certa medida amenizado nas teorias médicas da Antiguidade (MICHAUX, 1973; PESSOTTI, 1994). Tal misticismo ampara, com propriedade, vinculações entre o sofrimento mental e sua generalização na loucura, e sua relação com demônio.

Há, no mundo medieval, variadas categorias de "loucos":

[...] os 'furiosos' e os 'frenéticos' que são doentes que se podia tentar tratar ou, mais frequentemente, encerrar em hospitais especiais [...]; os 'melancólicos', cuja esquisitice talvez fosse também física, ligada aos maus humores, mas que necessitavam mais de padre que de médico; enfim, a grande massa de possuídos que só o exorcismo podia livrar de seu perigoso hóspede (LE GOFF, 2005, p.319).

Esta última categoria, a dos "possuídos" foi a mais festejada - e talvez mais cercada de simbolismos e discursos -, a categoria que formou uma "grande massa dos possuídos", consolidando o perfil de uma certa regra para os eventos envolvendo o sofrimento mental e, mais especificamente o grande rol de comportamentos e manifestações adjetivadas como loucura no mundo medievo.

A doutrina demonista instalava-se no imaginário popular a partir de dois fatores concorrentes: de um lado o cultuado medo ao demônio; de outro lado, a ignorância - no sentido lato de ignorar - ou da impossibilidade coetânea de produzir conhecimento capaz de explicar por outras vias determinados comportamentos e manifestações, dada a ausência de uma racionalidade técnica que só posteriormente veio a emergir, deixando as possíveis explicações para o campo das crendices e superstições.

Mesmo vindas de crenças, medos e superstições, as justificativas da doutrina demonista eram complexas e tomadas por detalhes. Por exemplo, haviam diferentes "escalas" de demônios: os de graus mais altos agiriam sobre o intelecto e forjariam situações imaginativas (RUSSEL, 2003), já os demônios de graus mais baixos teriam a mente similar a de um animal. Tais demônios "mais baixos" "precipitam-se cruelmente sobre nós, causando doenças e acidentes fatais, e nos possuindo. É por isso que as pessoas possuídas frequentemente exibem um comportamento animal" (RUSSEL, 2003, p. 38).

Assim, a identificação da perturbação da razão em sua generalização "loucura" com a possessão demoníaca foi uma interpretação comum na Idade Média, cujas origens remontam aos primórdios do cristianismo, quando a mitologia demonista já se fazia presente, 
sendo herdada de crenças pagãs pré-existentes, com as quais os padres dos primeiros séculos do cristianismo nutriam suas especulações sobre as interferências do demônio na mente das pessoas. No entanto, tais leituras ganharam fôlego e implicações morais e políticas através de sua formalização nos escritos de Agostinho de Hipona, mais conhecido como Santo Agostinho (354-430) e mais tardiamente com Tomás de Aquino (1225-1274) (PESSOTTI, 1994).

Sob declarada influência platônica, a dualidade mente $x$ corpo impregna os escritos mais relevantes do cristianismo medieval, havendo uma exaltação da alma e um rechaço da experiência corpórea, bem como de tudo o que era vinculado ao prazer carnal. A exemplo disso, como propõem os escritos agostinianos, mesmo a portadora de um corpo maculado por violência ou desejo alheio, pode preservar-se casta, desde que sua alma assim se conserve pela manifestação de uma profunda conviç̧ão (AGOSTINHO, 1964). Do mesmo modo, recorrendo a princípios físicos elementares e, ora compactuando com a autoridade de Platão, frente na proposição da dualidade mente $\mathrm{x}$ corpo, ora negando suas posições, quando sustenta a possibilidade de três almas sediadas em partes distintas do corpo, Tomás de Aquino sustenta que a existência intelectual não pertence à ordem do corpóreo e do material. A alma toca o corpo, mas não se mistura a ele em essência (AQUINO, 1953). Por indução, pode-se pensar que as afecções mentais, enquanto males que afetam a alma, sejam também derivadas de causas incorpóreas.

Agostinho, dialogando com escritos gregos e com demais crenças pré-cristãs, discorre longamente acerca dos demônios, esses seres que habitam um espaço intermediário entre o celeste e o terreno (seriam eles "aéreos"). Tais seres seriam capazes de interferir nas paixões humanas (tomando pathos como aquilo que afeta a razão) e no destino das coisas, bem como de interceder junto às divindades para a obtenção de benefícios pessoais. É curiosa a posição de Agostinho frente a esta problemática: não se admite a inexistência dessas criaturas, mas sim, se condena com veemência o culto a elas e os meios pelos quais o sujeito poderia vir a coopta-las a seu favor (a magia, o culto aos demônios, a feitiçaria, etc.) (AGOSTINHO, 1964). Nota-se aí uma restrição no âmbito das práticas religiosas, acentuando o "caráter correto" das práticas cristãs.

Para além da existência social e moral, o próprio corpo feminino era envolto por tabus de toda ordem, sobretudo no tocante a sua constituição e as diferentes funções de seus órgãos, abrindo flancos para as mais diversas interpretações sobre o que ocorria com o corpo 
feminino e para a associação deste à loucura. Considerando a questão a partir do foco atual, "enlouquecer" no mundo medievo já seria em si desastroso, pela interpretação em relação ao tema e pela falta de recursos terapêuticos para seu manejo. Mas quando o sujeito acometido pertencia ao sexo feminino, as concepções misóginas e machistas, místicas e supersticiosas do mundo medieval potencializavam o sofrimento a partir das relações de gênero. Assim, passar por esta experiência era absurdamente diferente para o homem e para a mulher, uma vez que a elas muito pouco era tolerado.

A condição feminina, desde a antiguidade, foi atrelada a uma espécie de demanda ou função social, na qual se concebia que a existência da mulher estaria subordina a função de ter filhos. A não satisfação desta inclinação conduziria inevitavelmente a um estado de sofrimento, a saber, a histeria (BIRMAN, 2001). A histeria até as portas do século XX foi pensada como uma afeç̧ão exclusivamente feminina, algo cuja origem deriva da suposta fraqueza e incompletude orgânica e moral da mulher, e aos movimentos e variações do órgão que lhe é exclusivo: o útero (que em grego denomina-se hystéra).

Este quando cuja origem é psicogênica, e que desde Freud (1992) é concebido como passível de ocorrência em homens e mulheres (hodiernamente denominado transtorno dissociativo ou de conversão, com uma variada gama de tipos descritos na Classificação Estatística Internacional de Doenças e Problemas Relacionados à Saúde, CID-10, realizado pela Organização Mundial da Saúde), é caracterizado por paralisias, anestesias, amnésias, transes, movimentos involuntários, perda da consciência auto e alopsíquica, perturbações sensoriais, estados semelhantes a convulsões, dentre outros sintomas.

Se a histeria serviu de modelo para a possessão demoníaca - tal sintomatologia pode ter originado a crença místico-religiosa da possessão. No contexto medieval, com parcos indícios de racionalidade científica, a loucura - seja em um quadro de histeria, ou mesmo pelo simples comportamento dissonante - restou por equiparar-se ao demônio, pois "como o discurso e o comportamento de maníacos, melancólicos, histéricos e paranoicos são, via de regra, incomuns, torna-se quase inevitável a atribuição dessas condutas a poderes demoníacos ou mesmo à possessão do louco pelo demônio" (PESSOTTI, 1994, p.89-90). Essa concepção opõe, diametralmente, a loucura à sanidade. A saúde, próxima a Deus. A loucura, vinculada ao demônio. Como aduz Ceccarelli:

A visão medieval da loucura está intimamente associada, ou mesmo 
identificada, à possessão demoníaca. Esta perspectiva ganha espaço à medida que a hegemonia do cristianismo se impõe. Derivam-se daí, por exemplo, as lutas contra os hereges que, por insistirem em cultuar divindades "pagãs", são vistos como encarnações do demônio (2005, p. 472).

A partir dessas construções mitológicas, houve um movimento de afirmação do poder ligado ao cristianismo, estabelecendo-se duas linhas evolutivas: primeiro, todas as divindades pagãs passam a ser tomadas como demônios; e segundo, todo dissidente do cristianismo passa a ser considerado um adepto ou instrumento do demônio, estando assim legitimada a perseguição e a intolerância religiosa (PESSOTTI, 1994).

Loucas ou bruxas por supostamente produzirem poções e realizarem rezas, simpatias e benzimentos, a vida destas mulheres também poderiam estar associadas à transgressões morais, como a prática da prostituição e do adultério (PEGORARO; CALDANA, 2008), ou ainda simplesmente por apresentarem comportamentos inadequados ou excêntricos para os padrões sociais vigentes, tratando-se de mulheres que, "não haviam se integrado à sociedade pelo casamento, procriação, produção doméstica, convertendo-se em sobrecarga para a época" (PEGORARO; CALDANA, 2008, p.85).

Em geral grassavam interpretações preconceituosas e simplistas em relação ao mundo que rodeava a mulher e qualquer desvio de padrão feminino então cultuado:

No geral pobres e de origem rural, as chamadas bruxas apresentavam condutas estranhas, indicativos de possessão demoníaca. Algumas dessas condutas assemelhariam-se a quadros, atualmente, descritos como histeria, melancolia, mania, depressão ou ansiedade. Além dessas condutas, outras características dessas mulheres seriam suas competências ou poderes anormais frente à sua condição social dentro da comunidade (PEGORARO; CALDANA, 2008, p.85).

Pelas doutrinas desenvolvidas por grandes nomes da teologia medieval antes mencionados, como Santo Agostinho e Santo Tomás de Aquino, consideravam-se obras do demônio diversas sensações, tentações e revezes que acometiam os sujeitos (PESSOTTI, 1994). Tais problemas poderiam ser propiciados pela ação da bruxaria e por rituais pagãos francamente combatidos, assim como pela fraqueza individual: o pecado. Dentre essas manifestações demoníacas encontram-se diversos quadros hoje compreendidos como psicopatológicos, como a depressão, a psicose e a histeria.

Quando se queimaram centenas de mulheres histéricas ou psicóticas, ou simplesmente ignorantes e crédulas sob a acusação de estarem mancomunadas com o demônio ou possuídas por ele, a "teologia" que embasará os "julgamentos" e interrogatórios será basicamente a de 
Agostinho, consolidada e aperfeiçoada por Tomás de Aquino. Cuja decantada inteligência não lhe impedirá de adotar numerosas crendices dos antigos Padres Apologistas. (PESSOTTI, 1994, p.87).

Parte considerável da literatura inquisitória e exorcista utilizou como base as ideias tomistas, e através de tais escritos, difundiu o temor pela ação dos demônios e de seus comparsas humanos, atestando a onipresença dos perigos e das tentações demoníacas. (Idem). Sobre o papel político da Inquisição, Gomes (1996) aponta que essa perspectiva,

(...) teve importante papel nas guerras religiosas do século XVI; ajudou a sedimentar a unidade religiosa que servia de base aos estados nacionais e à colonização; participou ativamente das tensões econômicas que marcaram o Antigo Regime. Acima de tudo, esteve presente no nível do cotidiano, submetendo crenças e afetos a um grau de controle jamais antes imaginado (p. 154).

Atribuía-se à ação demoníaca uma série de comportamentos pouco usuais o que lançou a população hoje concebida como doente pela psiquiatria moderna, dentro de categorias religiosas como a possessão ou a obsessão. No entanto, não se encontram raciocínios que coloquem a possessão como causa da loucura, tomando-a como um quadro específico, antes, toda a sintomatologia é a própria expressão do diabo, em uma espécie de inversão da leitura mitológica grega, na qual a loucura era um produto da ação sobrenatural sobre a paixão humana. "Não se afirma algo como 'possesso, portanto louco', mas 'louco, portanto possesso'" (PESSOTTI, 1994, p.90), a loucura ganha tons maléficos em si, não havendo a possibilidade de uma leitura positiva deste estado, como ocorria na Antiguidade momento em que ela podia ser concebida como uma situação que visava à reparação de um dano e o alcance de uma condição de equilíbrio. Em tempos medievais, a loucura é necessariamente má, e o louco é passivo frente às forças demoníacas, bem como frente ao poder do exorcista, não havendo espaço para a autoconsciência. "A perda da razão ou o descontrole emocional agora têm a marca da condenação e da culpa. O louco passa a ser suspeito, a ser perigoso e, por isso, evitado" (PESSOTTI, 1994, p. 100).

Assim, na idade Média a pessoa com alguma deficiência ou comportamento aberrante - incluindo neste leque todas as categorias hoje concebidas como doenças mentais - era vista como "expiador de culpas alheias, ou um aplacador da cólera divina a receber, em lugar da aldeia, a vingança celeste, como um para-raios" (PESSOTTI, 1994, p.5-6), em uma exacerbação do binômio culpa/castigo.

\section{Sobre a "cura": expiação, castigo e corpo feminino}


Uma das obras mais conhecidas acerca das possessões demoníacas e da bruxaria, que apresenta indiretamente a interpretação teológica medieval da loucura é Malleus Maleficarum, de autoria de Heirinch Kramer (1430-1505) e James Sprenger (1436-1495), escrito em 1484, livro que toma os textos de Aquino como uma espécie de "aporte teórico", ao sustentar que a mulher, desde a criação do mundo, é mais suscetível ao pecado, e que serviu de manual às investidas da religião contra as bruxas, pessoas sobre as quais se cometeram as mais diversas atrocidades, ações que contribuíram para ligar a loucura ao erro e à imoralidade.

De todas as rupturas que poderiam ocorrer entre a cosmovisão medieval e o mundo moderno - para além das datações civis de alteração do período -, as premissas da obra Malleus Maleficarum representam certo ápice da interpretação medieval para as possessões, sobretudo no que tange a mulher, como retratado no excerto abaixo:

Mas a razão natural está em que a mulher é mais carnal do que o homem, o que se evidencia pelas suas muitas abominações carnais. E convém observar que houve uma falha na formação da primeira mulher, por ter sido ela criada a partir de uma costela recurva, ou seja, uma costela do peito, cuja curvatura e, por assim dizer, contrária à retidão do homem. E como, em virtude dessa falha, a mulher é animal imperfeito, sempre decepciona e mente (KRAMER; SPRENGER, s/d, p. 116).

Escrito por solicitação do Papa Inocêncio VIII (1432-1492), neste livro encontram-se diversas menções a quadros, hodiernamente "sintomáticos", como a ilusão, o delírio e a alucinação, e curiosas observações acerca da sexualidade das bruxas, sendo que diversos capítulos se referem a este tema. Importa lembrar ainda que não existem pactos demoníacos envolvendo homens, a não ser que estes sejam seduzidos e "ingenuamente" utilizados para a obra necessária à mulher/bruxa.

Interessante observar que, se a mulher fosse velha e estéril, poderia ser uma bruxa. Mas também, se fosse jovem e fértil poderia ser uma bruxa. Não havia regras, a não ser a disposição arbitrária do corpo feminino para toda uma gama de leituras e diagnósticos de seu comportamento:

Nenhuma regra infalível pode ser estabelecida a este respeito, mas existe uma distinção provável: que uma bruxa ou é velha e estéril ou não é. E se ela o é, então ele naturalmente se associa à bruxa sem injeção de esperma, desde que isso seria inútil e o diabo evita tanto quanto possível tudo o que é supérfluo em suas obras. Porém, se ela não é estéril, ele dela se aproxima na forma de um deleite carnal que é procurado pela bruxa. E se ela estiver 
predisposta à gravidez, então ele se apossa devidamente do sêmen de algum homem, e não tarda em se aproximar dela com a finalidade de infectar sua descendência (KRAMER; SPRENGER, s/d, p. 58).

A obra acima citada está repleta de inquietações de ordem sexual, sejam elas de cunho puramente fantasioso, como o trecho citado acima, sejam problemas concretos, como é o caso da impotência sexual, que recebia este mesmo tipo de interpretação, neste caso, imbuindo de culpa a figura da mulher/bruxa que, muitas vezes, era uma jovem que não retribuiu os apelos amorosos de seu admirador, e que promoveu uma "extirpação fictícia", via feitiço, do órgão fálico. Sobre esta ênfase sexual no trato com a bruxaria, pode-se interpretar,

Como fator chave na diabolização da mulher, a sexualidade feminina apresenta-se sempre acompanhada de insaciedade, produzindo-se, assim, a imagem da bruxa voraz, a ogra devoradora que engole todos os seus filhos. Talvez como subproduto da miséria, sua fúria é o resultado de um imenso apetite impossível de ser satisfeito. Essa fome é intensificada no sexual e vem impressa no mito da avidez vaginal, sendo a boca da vulva considerada como a parte mais insaciável da mulher. Seus aspectos noturnos, funestos e lunares afastam-na das racionalidades. (ZORDAN, 2005, p. 337-338).

Esta atenção dada à influência da bruxaria sobre a sexualidade, bem como a descrição e algumas possessões (em que o demônio se apossa do corpo) ou obsessões (em que o demônio influencia o pensamento e as ações do sujeito), remetem a quadros clínicos descritos pelas ciências da mente, em especial, a quadros de histeria, os quais Freud (1992) em fins do século XIX expôs a etiologia ligada à vida sexual em sentido amplo, para além da genitalidade feminina.

O período medieval foi assinalado por uma mentalidade misógina e discriminatória, mentalidade que em nada preocupava-se com o sofrimento feminino, mas centrava esforços em refrear os seus impulsos sexuais, sobretudo através da demonização, pois "mesmo nas velhas, a presença de todo um clamor desejante e de inevitáveis atribuições fálicas faz de todas as bruxas figuras sexualizáveis por excelência. Como fator chave na diabolização da mulher, a sexualidade feminina" (DELUMEAU, 1989, p. 327).

A mulher detinha - por características biológicas inerentes a sua condição de gênero -, supostos segredos e peculiaridades que a vinculavam de forma acentuada às forças da natureza: "porque mais próxima da natureza e mais bem informada de seus segredos, a mulher sempre foi creditada, nas civilizações tradicionais, do poder de não só profetizar, mas também de curar ou de prejudicar por meio de mistérios e receitas" (DELUMEAU, 1989, p.311). 
Thomas Szasz (1979), ao ponderar sobre a compreensão de bruxaria como uma interpretação errônea de um quadro psicopatológico que depois seria denominado como histeria, avalia a função moral do suplício das bruxas na Idade Média, sobre o qual ele pondera que não seria uma "má interpretação" de uma doença, pois, primeiramente, não haveria neste período uma medicina capaz de comportar este transtorno em sua nosologia, e segundo, a racionalidade da época não é a mesma dos tempos científicos. Ele afirma que

O interesse pelas atividades sexuais das bruxas era uma contrapartida, uma imagem especular da atitude oficialmente anti-sexual da Igreja Católica. A tortura e a queima das bruxas deve ser vista à luz da visão teológica do mundo medieval, segundo a qual o corpo é fraco e pecador, e o único objetivo que vale a pena ser atingido pelo homem é a salvação eterna de sua alma (SZASZ, 1979. p.166-7).

Neste sentido, o uso da tortura, permitido no intuito de se obter uma confissão, foi legitimado pelo papa Inocêncio IV, em 1252 e era aplicada sempre que se suspeitasse de uma confissão, ou quando esta fosse contraditória com as demais provas recolhidas, e vale lembrar que um único testemunho de atividades da suposta bruxa já era condição suficiente para instauração de um inquérito.

O inquérito e a tortura tinham uma conotação sexual quase explícita, basta verificar a prática de interrogar as supostas bruxas sempre despidas. Aliás, a nudez feminina parecia exercer um fascínio sobre os inquisidores. A quase totalidade das gravuras sobre o assunto mostram corpos femininos desnudos, bem como "os processos de bruxaria tinham um considerável enfoque nos corpos das bruxas: elas eram desnudadas à procura de um sinal que as pudesse recriminar" (ZORDAN, 2005, p. 335).

Em outro trecho do Malleus Maleficarum, por exemplo, são descritos os procedimentos de investigação através do interrogatório, e justificados procedimentos invasivos, desvelando e desnudando o corpo, no qual,

(...) os pelos e cabelos devem ser raspados de todo o seu corpo. A razão para isso é a mesma porque se deve tirar-lhes as roupas [...]; pois para conservarem o poder do silêncio têm o hábito de esconder objetos supersticiosos nas roupas e nos cabelos, até mesmo nas partes mais secretas do corpo (KRAMER; SPRENGER, s/d, p. 158).

A condição de bruxa forjou uma leva de bodes expiatórios, sobre os quais se aplicam as punições exemplares em prol de uma conduta moralmente adequada e da salvação comum (processo que se repete nas diversas sociedades, mudando os sujeitos focalizados e os 
procedimentos tomados), onde a única interpretação viável, na época, era a teológica, que constituía a racionalidade dominante (SZASZ, 1979).

Queimar corpos humanos na fogueira era um ato simbólico que expressa a adesão às regras oficiais do jogo. Essa afirmação dramática e ritualizada da fé assegurava a existência continuada de uma importante ficção ou mito social. Queimar bruxas acusadas durante a caça às bruxas pode ser, portanto, comparado à destruição de bebidas confiscadas na época da Lei Seca. Ambos os atos expressavam o reconhecimento oficial a uma regra que poucas pessoas na verdade seguiam. (Idem, p.167).

O mesmo autor traça um paralelo entre a bruxaria e a doença mental, em que, de forma semelhante, ninguém se intitulava bruxa, do mesmo modo que ninguém assume de bom grado ser um "doente mental", esses dois processos se fazem "de fora", são atributos imputados pelo discurso oficial da sociedade, e que implicam sérias restrições ao sujeito assim classificado. Continuando a comparação, os sujeitos tomados como bruxos eram em sua maioria mulheres pobres, velhas e fracas, raros eram os casos em que homens, assim como pessoas de alto nível social, eram condenados por bruxaria; do mesmo modo, as ações mais incisivas da psiquiatria se deram (ou se dão) sobre sujeitos social e economicamente desamparados (SZASZ, 1979).

O problema do olhar medieval sobre a loucura não era a falta de um escopo clínico sobre as mulheres acusadas, impossível no enquadre epistêmico da época, trata-se antes de uma condição correlata a que a mulher "histérica" do século XIX e início do século XX sofria, ou seja, condição de amplas restrições sociais. Considerando-se as características cada tempo, as histéricas da medicina de pouco mais de cem anos atrás, eram submetidas a processos semelhantes aos aplicados às bruxas, entretanto, no lugar do interrogatório do religioso e da fogueira, tem-se o escrutínio do médico, e as frequentes internações em sanatórios. Nos dois casos, há a problemática da dominação, oficialmente determinada e exercida como algo natural, e da submissão cotidiana, que vinculou a feminilidade a uma aceitação dócil de sua condição supostamente inferior, condição em que a bruxaria ou a histeria serviram de linguagem a um discurso subversivo, que denuncia a opressão (SZASZ, 1979). Discurso este que a Psicanálise, ao dar voz aos sujeitos em sofrimento no início do século XX, buscou decifrar, apontando outros destinos possíveis para a vida desses, antes condenados a restritas experiências sociais, sempre pautadas por sua condição de sujeição e pelos precários meios de contenção do mal que as afligia (BIRMAN, 2001). 


\section{Considerações finais}

No mundo medievo, o medo grassava. Temia-se tudo. "O distante, a novidade e a alteridade provocavam medo. Mas temia-se do mesmo modo o próximo, isto é, o vizinho." (DELUMEAU, 1989. p. 82). De igual sorte, temia-se o demônio, a loucura e, - por ser obra do demônio -, e a mulher...

Assim na Idade Média, alguns dos discursos pronunciados sobre a loucura restavam por emparelha-la ao feminino, ao corpo, à moral e aos atos desse gênero, alvo das mais diversas restrições. A este emparelhamento, vieram somar-se as doutrinas demonistas e o quase fetiche pelo acesso ao corpo feminino pois, se a loucura se consubstanciava em um fenômeno iminentemente feminino e diabólico, o expurgo para tal diagnóstico viria através do corpo da mulher.

O corpo feminino foi, reiteradas vezes, considerado morada para toda sorte de loucuras sendo que, no contexto em estudo, a loucura transcendia qualquer parâmetro de ciência. As loucas eram espancadas; as bruxas eram queimadas, e o corpo das mesmas era depositário para as consequências do sofrimento e para a ostentação do rigor moral, pois avigorava a ideia de que a condição feminina era, em si, maléfica.

Os discursos prenotados pela Idade Média sublinharam a ideia de indexação do feminino ao pecado original e a perdição da humanidade, reeditando em cada mulher o perfil de uma Eva. A Idade Média produziu - como todas as demais épocas -, a sua verdade e,

(...) a verdade é deste mundo; ela é produzida nele graças a múltiplas coerções e nele produz efeitos regulamentados de poder. Cada sociedade tem seu regime de verdade, sua "política geral" de verdade: isto é, os tipos de discurso que ela acolhe e faz funcionar como verdadeiros; os mecanismos e as instâncias que permitem distinguir os enunciados verdadeiros dos falsos, a maneira como se sanciona uns e outros; as técnicas e os procedimentos que são valorizados para a obtenção da verdade; o estatuto daqueles que têm o encargo de dizer o que funciona como verdadeiro (FOUCAULT, 2002, p. 12).

Deste modo, sofrer fazia parte do papel feminino e os saberes da época operaram suas justificativas, instaurando-as como verdades, visto a necessidade de "expiar" a perdição de suas antecessoras, bem como contrapor seus efeitos sobre o desejo masculino, ponto este, em que a suposta fraqueza carnal masculina era amplamente projetada sobre o corpo feminino, responsabilizando-o por qualquer ação irracional proveniente deste desejo.

As mostras da loucura, consideradas como "manifestações do funcionamento 
psicológico que aparecem tanto na pessoa que os experimenta ou aos olhos do observador, como anormais" (NEMIAH, 1981, p.238), foram utilizadas como argumento cabal em uma espécie de "limpeza de gênero" na Idade Média e parte da Idade Moderna - considerada a extensão temporal da Inquisição, poderoso dispositivo constituído naquele contexto -, no qual o comportamento indesejado ou excêntrico, muitas vezes fruto do sofrimento individual e das dificuldades sociais, serviram de pretexto para a afirmação de um parâmetro falocêntrico de normalidade, considerada a partir de valores morais, políticos e econômicos vigentes.

\section{REFERÊNCIAS}

AgOSTINHO. A cidade de Deus. São Paulo: Das Américas, 1964.

AQUINO, Tomas de. Sumula contra los gentiles. v.1. Madrid: Ed. Católica, 1952.

BIRMAN, Joel. Gramáticas do erotismo. Rio de Janeiro: Civilização Brasileira, 2001.

CECCARELLI, Paulo. O sofrimento psíquico na perspectiva da psicopatologia fundamental. Psicologia em Estudo, Maringá, v. 10, n. 3, p. 471-477, set.- dez. 2005.

DELUMEAU, Jean. História do medo no ocidente: 1300 - 1800. São Paulo: Companhia das Letras, 1989.

FOUCAULT, M. Microfísica do poder. 17.ed. São Paulo: Graal, 2002.

GOMES, Plínio José Freire. Brincando com fogo: o acervo do Santo Ofício como fonte (só) para historiadores. In: MALERBA, Jurandir (org.). A velha história: teoria, método e historiografia. Campinas, SP: Papirus, 1996. p. 153-169.

FREUD, Sigmund. Obras Psicológicas Completas. Rio de Janeiro: Imago, 1992.

KRAMER, H.; SPRENGER, J. Malleus Maleficarum: Manual de caça às bruxas. São Paulo: Ed. Grupo Três, $\mathrm{s} / \mathrm{d}$.

LE GOFF, Jacques. A Civilização do Ocidente Medieval. Bauru: Edusc, 2005.

MICHAUX, Leon. Os graus da loucura: seus sintomas e seus remédios. Rio de Janeiro: Civilização Brasileira, 1973.

NEMIAH, J. C. Fundamentos da psicopatologia. 3a ed. Rio de Janeiro (RJ): Zahar Ed; 1981.

PEGORARO, Renata Fabiana; CALDANA, Regina Helena Lima. Mulheres, loucura e cuidado: a condição da mulher na provisão e demanda por cuidados em saúde mental. Saúde e Sociedade. São Paulo: USP, v. 17, n. 2 , jun. 2008 , p.82-94.

PESSOTTI, Isaias. A loucura e as épocas. São Paulo: Ed. 34, 1994.

RUSSEL, Jeffrey Burton. Lúcifer: o Diabo na Idade Média. Editora Masdra, 2003.

SILVA, Otto Marques da. A Epopeia Ignorada: A História da Pessoa Deficiente no Mundo de Ontem e de Hoje; São Paulo: CEDAS, 1987. 
SZASZ, Thomas S. O mito da doença mental. Rio de Janeiro: Jorge Zahar, 1979.

ZORDAN, Paola Basso Menna Barreto Gomes. Bruxas: figuras de poder. Rev. Estudos Feministas. Florianópolis, agosto/2005, vol.13, n.2, p. 331-341. 